\title{
Use of Botanical Pesticides in Controlling Sitophilus Zeamais (Maize Weevil) on Stored Zea Mays (Maize) Grain
}

\author{
Parwada Cosmas*, Chikuvire T John, Kamota Agathar, Mandumbu Ronald, Mutsengi Kufa and Chiripanhura Betty \\ Department of Crop Science, Bindura University of Science Education, Zimbabwe \\ *Corresponding author: Parwada Cosmas, Department of Crop Science, Bindura University of Science Education, P. Bag 1020 Bindura Zimbabwe
}

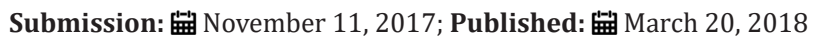

\begin{abstract}
Sitophilus zeamais (maize weevil) is a field and storage pest of maize of economic importance in several parts of Africa. Controlling of the pest by use of synthetic pesticides is raising serious concern on the environmental safety and consumer health hazards. A laboratory experiment was done to assess three botanicals, Eucalyptus terreticonis, Tagetes minuta and Lantana camara, in controlling the S. zeamais. A Completely Randomised Design (CRD) with three application rates (5g/200 g grain, $10 \mathrm{~g} / 200 \mathrm{~g}$ grain and $20 \mathrm{~g} / 200 \mathrm{~g}$ grain) of the botanicals replicated three times was used in the assessment. A synthetic chemical (pirimiphos-methyl) was used as a control pesticide to compare the efficacy of the botanicals on the maize weevil. The results showed higher weevil mortality and lower grain loss in the pirimiphos-methyl than in the botanicals (P<0.05). The botanicals had significant difference on weevil mortality rates where the Eucalyptus terreticornis recorded highest mortalities followed by Tagetes minuta and Lantana camara at $20 \mathrm{~g} / 200$ grain application rates respectively. The efficacy of the botanicals significantly $(\mathrm{P}<0.05)$ decreased with time after application of the botanical powder. The Eucalyptus terreticornis at $20 \mathrm{~g} / 200 \mathrm{~g}$ grain showed potential in controlling the $S$. zeamais and therefore may be used to protect maize grain damage from the weevil during storage. However, with a constant re-application of the botanical powder is necessary in order to maintain the efficacy at high levels.
\end{abstract}

Keywords: Botanicals; Efficacy; Synthetic pesticide; Pest; Maize

Abbreviations: CRD: Completely Randomised Design; OPMVs: Open Pollinated Maize Varieties; ARDA: Agricultural Rural Development Authority; OPv: Open Pollinated varieties

\section{Introduction}

Zea mays (maize) is a staple crop in many African countries [1]. It is grown both on commercial or subsistence levels and in most cases produced in abundance such that it requires storage for future use [2]. Maize is a high yielding crop attaining an average yield of up to 8 t/ha, easy to process, readily digested and cheaper to produce than any other cereals [3]. Many smallholder maize producing farmers in developing countries live in remote and inaccessible areas characterised by poor road networks making it difficult to dispose their produce to the market. The farmers therefore require to store their grain for long, up to 6-8months after harvest and the Sitophilus zeamais (maize weevil) is a menace during this period. According to Morris (2001), 50\% of resource poor farmers, especially in Zimbabwe are still using traditional Open Pollinated Maize Varieties (OPMVs) which are not resistant to the maize weevil damage regardless the need to retain seed for the next crop and for food. This lead to serious food insecurity among the farmers. The S. zeamais is one of the stored maize pests of economic importance in most parts of Africa [4]. The pest damage result to direct food loss and may also reduce future maize production for farmers who retain grain as seed. Apart from weight loss, the $S$. zeamais also reduce the aesthetic and market value, germinability and nutritive value of grain [3].

Currently, the control of this insect pest relies heavily on use of synthetic insecticides e.g. but have a number of draw backs such as development of resistance, toxic residues, worker safety and increased costs of application [2]. Concerns over human health and environmental problems associated with the use of synthetic pesticides in agriculture have led to an intensification of efforts to find safe, effective and viable alternatives. In this regard plant based pesticides can be less toxic, readily biodegradable, suitable for use by small scale farmers and capable of protecting grain from pest [2]. Also poor storage facilities in the developing countries renders use of the synthetic chemicals ineffective and pest resistance to chemicals as most storage structures are prone to pest re-infection resulting to shorter pesticides reapplication intervals [5]. Coupled with the inauspicious macro-economic environment in most developing countries like Zimbabwe, the resource constrained farmers cannot easily access the synthetic chemicals to preserve 
their grain amounting to huge storage losses. The farmers have been since using local plants and other remedies to control the storage pests, little is known about their efficacy [6]. Most botanicals are locally available to the farmers. They do not have any residual effect and therefore environmentally friendly. Botanicals are quick to stop feeding of insect pests and often cause immediate paralysis or cessation of feeding, although may not cause the insect's death for hours or days.

Communal smallholder farmers use different kinds of plant products to control storage grain pests. The precise strategy used these farmers varies from place to place and appears to depend partly on the type and efficacy of suitable materials available in different locations [7]. There are a variety of botanical which are used by farmers for examples Lippia javanica, Eucalyptus spp and Tagetes minuta [4]. Many African plants are potential sources of pesticide and have been shown to contain either anti- feedant, repellent or insecticidal compound that enable the crude plant material or an extracted active compound to protect stored product [8]. Researches on plants with repelling effect on pests are being done in some parts of Africa, but have not yet gained much publicity [9]. Therefore the objective of this study was to determine the efficacy of three plants (Lantana camara, Tagetes minuta and Eucalyptus terreticornis) on weevil mortality and the extent of maize grain weight loss. We hypothesised that a botanical treatment that with highest mortality rates and lowest grain weight loss has highest efficacy on the S. zeamais.

\section{Materials and Methods}

\section{Site description}

The study was carried out in the Physics laboratory at the Bindura University of Science Education, Zimbabwe. The university is in the Mashonaland Central Province of Zimbabwe which lies in agro-ecological region II b. It receives an average rainfall of $1200 \mathrm{~mm} /$ annum. Temperature in the laboratory ranged from 25 $30 \mathrm{oC}$ and the relative humidity also varied from $65-75 \%$ during the experimenting period. The laboratory was kept well aerated throughout the study.

\section{Materials}

An open pollinated maize grain, ZM 521 variety sourced from the Agricultural Rural Development Authority (ARDA) Nijo Zimbabwe was used. An open pollinated varieties (OPv) was used because it has stable yields in adverse conditions such as drought due to heterogeneity and commonly grown by most resource poor smallholder farmers. The grain was sieved to remove dead seed, dirty and broken particles, $10 \mathrm{~kg}$ grain was randomly sampled and stored in a freezer at -4 oC for 2 weeks to kill any prior sources of the S. zeamais inoculum and eggs which might be already pre-existing in the grain. After 2 weeks in the freezer, subsamples of $200 \mathrm{~g}$ grain were put in $375 \mathrm{ml}$ bottles with perforated lids to prevent weevils from escaping and for aeration.

The botanical pesticide leaves (Eucalyptus terreticonis, Lantana camara and Tagetes minuta) were collected and naturally dried at temperatures between 26-28 oC for five days until crisp dry. The dried leaves were then crushed and sieved using a $0.5 \mathrm{~mm} \emptyset$ mesh size. Then varying quantities $(5 \mathrm{~g} / 200 \mathrm{~g}$ grain, $10 \mathrm{~g} / 200 \mathrm{~g}$ grain and $20 \mathrm{~g} / 200 \mathrm{~g}$ grain) of each botanical were measured and thoroughly mixed with the grain and kept at room temperature for 9 weeks. A control of synthetic pesticide (pirimiphos-methyl) was used at a label rate of $0.175 \mathrm{~g} /$ bottle and untreated grain were included in the experiment. The initial generation of grain weevils were collected from a farmer in the Dande Valley, Zimbabwe. The rearing of initial generation of unsexed $S$. zeamais was done in the laboratory to obtain uniform population of weevils. The newly emerged weevils were sexed and 10 males and 10 females were put in each bottle with maize grain.

\section{Experimental Design}

A $3 \times 3$ factorial experiment laid in a Complete Randomised Design (CRD) replicated three times was used in the arrangement of the bottles.

\section{Data collection}

The study ran for three months, from February-April 2011. Weevil mortality rates were measured by physically counting dead weevils at a 2 week interval. The mortality counts were done during the day when the weevils were highly active due to high temperatures and relative humidity. The weevil counts were expressed as percentage.

Grain loss assessment was done using Thousand Grain Method (TGM) as follows:

$$
T G M=\frac{\text { initial } T G M-\text { final } T G M}{\text { initial } T G M \times 100}
$$

Mass of 1000 grains at the beginning of the storage period was compared with mass of 1000 grains at the 2 week intervals during the experiment.

\section{Data analysis}

Analysis of variance (ANOVA) to compare mean weevil mortality rates and percentage grain weight losses was done using GENSTAT version 12 . The weevil percentages counts were normalise by square root transformation before analysis.

\section{Results and Discussion}

\section{Variations in weevil mortality among the botanicals}

The efficacy of the botanicals on the S. zeamais were significantly $(\mathrm{P}<0.05)$ different. Highest and lowest mortalities were recorded on E. terreticonis and L. camara respectively (Table 1). The synthetic chemical recorded 100\% mortalities at 0.4weeks after weevil inoculation and the untreated bottles had lowest mortality rates (Table 1).

The weevil mortality rates increased from week 0.4 and was maximum at week 5 after weevil inoculation thereafter decreased gradually until week 9 in all the botanicals (Table 1). 
Table 1: Efficacy of different treatments on weevil mortality.

\begin{tabular}{|c|c|c|c|c|c|c|}
\hline \multirow{2}{*}{ Treatments } & \multicolumn{6}{|c|}{ Time (weeks) } \\
\hline & 0.4 & 1 & 3 & 5 & 7 & 9 \\
\hline E. terreticonis & $32.94^{\mathrm{a}}$ & $43.83^{\mathrm{b}}$ & $70.11^{\mathrm{a}}$ & $90.56^{\mathrm{a}}$ & $81.83^{\mathrm{a}}$ & $21.56^{\mathrm{a}}$ \\
\hline T. minuta & $13.17^{\mathrm{b}}$ & $52.72^{\text {a }}$ & $60.78^{b}$ & $60.11^{\mathrm{b}}$ & $63.11^{\mathrm{b}}$ & $12.28^{\mathrm{b}}$ \\
\hline L. camara & $2.50^{c}$ & $22.50^{c}$ & $27.06^{c}$ & $34.39^{c}$ & $21.78^{c}$ & $9.7^{\mathrm{b}}$ \\
\hline Pirimiphos-methyl & $100^{\mathrm{d}}$ & $100^{\mathrm{d}}$ & $100^{\mathrm{d}}$ & $100^{\mathrm{d}}$ & $100^{\mathrm{d}}$ & $100^{\mathrm{d}}$ \\
\hline Untreated grain & $3.9^{c}$ & $5.5^{\mathrm{e}}$ & $4.7^{\mathrm{e}}$ & $7.02^{\mathrm{e}}$ & $5.2^{\mathrm{e}}$ & $6.02^{\mathrm{b}}$ \\
\hline Lsd & 3.11 & 1.34 & 6.11 & 2.93 & 6.23 & 6.7 \\
\hline Sed & 1.12 & 0.48 & 2.2 & 1.05 & 2.24 & 2.48 \\
\hline Cv\% & 8.5 & 1.8 & 7 & 2.5 & 8.3 & 19.2 \\
\hline$P$ value & 0.001 & 0.001 & 0.002 & 0.001 & 0.001 & 0.006 \\
\hline
\end{tabular}

Means followed by the same letter in a column are not significantly different from each other at $\mathrm{P}<0.05$.

The weevil mortality rates were significantly $(\mathrm{P}<0.05) \quad(20 \mathrm{~g} / 200 \mathrm{~g}$ grain $)$ the rate of application, the higher the mortality influenced by the botanical application rates (Table 2). The higher rates recorded (Table 2).

Table 2: Efficacy of botanicals application rates on weevil mortality.

\begin{tabular}{|c|c|c|c|c|c|c|}
\hline Time (weeks) & 0.4 week & week 1 & week 3 & week 5 & week 7 & week 9 \\
\hline \multicolumn{7}{|c|}{ Rate } \\
\hline $5 g$ & $11.83 \mathrm{~b}$ & $28.72 b$ & $26.17 \mathrm{~b}$ & $34.06 \mathrm{~b}$ & $18.83 \mathrm{~b}$ & $8.72 b$ \\
\hline $10 \mathrm{~g}$ & $15.83 a$ & $34.33 a$ & $34.39 \mathrm{a}$ & $55.17 \mathrm{a}$ & $35.06 a$ & $18.06 \mathrm{a}$ \\
\hline $20 \mathrm{~g}$ & $20.94 \mathrm{c}$ & $36.00 \mathrm{c}$ & $55.39 \mathrm{c}$ & $84.83 c$ & $75.17 \mathrm{c}$ & $20.83 c$ \\
\hline Lsd & 1.77 & 1.152 & 2.594 & 1.865 & 2.712 & 2.361 \\
\hline Sed & 0.858 & 0.558 & 1.257 & 0.904 & 1.314 & 1.144 \\
\hline P value & 0.001 & 0.001 & 0.001 & 0.001 & 0.001 & 0.001 \\
\hline $\mathrm{CV} \%$ & 15.9 & 5.1 & 9.8 & 5.3 & 11.9 & 21.6 \\
\hline
\end{tabular}

Means followed by the same letter in a column are not significantly different from each other at $\mathrm{P}=0.05$.

The effects of different plant materials on insects may depend on several factors such as chemical composition several factors such as chemical composition and species susceptibility [10]. In the present study, mortality of Sitophilus zeamais varied with the dosage of the plant species. The findings of this study showed that an increase in the botanical concentration results in a reduction in the incidence of weevil attack. The Eucaluptus terreticornis leaves were effective in controlling the weevil as compared to Tagetes minuta and Lantana camara. In related studies by Mbaiuinam et al. [6], where ground Eucalyptus saligna leaves Cypress leaves showed that grounding the leaves allows them to release their insecticidal effect on weevils.

The weevil mortality in the untreated grain might be due to disturbances or genetic weaknesses. The untreated grain offers free environment where weevils suffer no developmental limitations hence the highest feeding rates. Conventional chemical control was more effective than traditional methods at $5 \mathrm{~g}, 10 \mathrm{~g}, 20 \mathrm{~g}$ levels of the botanicals used. However greatest effectiveness of the botanical pesticides was observed at 20g Eucalyptus terreticornis. The use of local plant products and other available materials to protect crop grain have been reported by other researcher [11] where maize cob ashes were used at different concentration to control maize weevils also showed that weevil mortality increases with increasing concentration of the ashes.

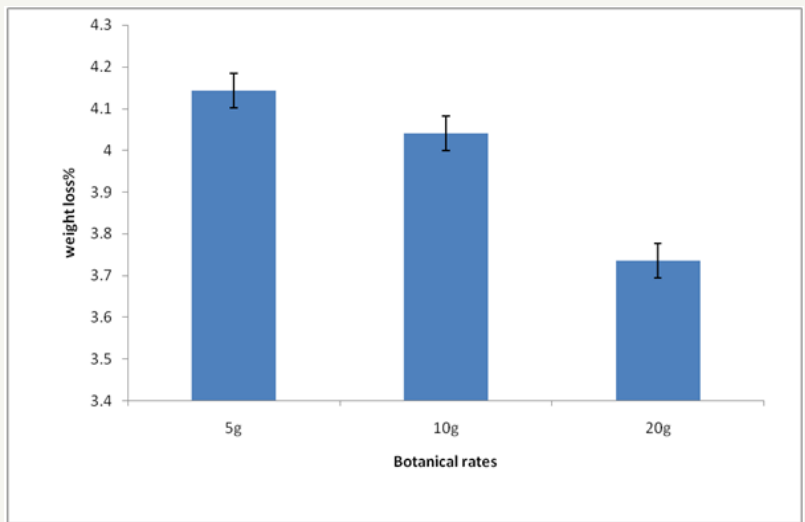

Figure 1: Effect of botanical application rates on grain weight loss (\%).

The results of the study also showed that the efficacy of botanical pesticides decreases with time as shown by the reduced mortality percentages from fortnight three. This suggests that botanical need constant reapplications for them to offer continual protection of the grain against maize weevils. Grain weight loss ranged from 3.7- 4.1\% (Figure 1). The grain weight losses were significantly $(\mathrm{P}<0.05)$ highest and lowest in $5 \mathrm{~g} / 200 \mathrm{~g}$ grain and 20 g/200g grain respectively (Figure 1). Weight loss varied from 3.74.1 as shown on the graph. The damage to grain shown by weight loss was highest on $5 \mathrm{~g}$ and lowest on $20 \mathrm{~g}$. 
There were significant variations in grain weight loss among the botanicals. The grain weight loss as influenced by the used botanicals ranked from highest to lowest as follows: Eucalyptus terreticornis > Tagetes minuta > Lantana camara. Untreated maize had the highest weight loss due to weevil damage compared to all the other treatments. According to Duke [12] weevils are capable of causing $80-100 \%$ weight loss if grain is left untreated for long periods. Conventional chemical control had insignificant weight loss. According to Dolob [13] synthetic insecticides offer no tolerance to weevil damage most synthetics are in dust form. The dusts inhibits egg laying and larval development of the weevils In the absence of synthetic pesticides, the E. terreticornis can be used to control the $S$. zeamais, as the plant has high repellent effects due to a strong aroma produced by the leaves.

Weevils cause qualitative and quantitative loss of stored grain [13]. They are capable of building up to very large numbers if left uncontrolled. This was shown by the high build-up of weevils in the untreated grain. The environment in the untreated grain offered free movement of the weevils as wells as high chances of mating leading to increased populations. He went on to say weevil can also cause secondary effects such as fungal infection leading to further weight loss. The synthetic chemical and E. terreticornis had lowest weight loss due to the fact that there was continual death of the weevils thereby reducing their damage threats (Sabramanyan and Roesli, 2000).

Despite the higher number of damaged grain in maize treated with Tagetes minuta and Lantana camara, the weight loss was low as compared to untreated grain. This suggests that these two botanicals exert better repellent effect and hence reduced maize grain damage [14]. The low quantity of maize loss observed in this study suggests that Eucalyptus leaf powder can be used as good alternative to synthetic pesticides against $S$. zeamais.

\section{Conclusion and Recommendation}

In the absence of synthetic chemicals, small holder farmers can use Eucalyptus terreticornis leaves. Crushing of E. terreticornis leaves enhanced contact between the maize grain and E. terreticornis powder hence lowered the weevil damage. The powders also have a tendency of blocking the spiracles of the insect thus impairing respiration leading to their death. The research findings also showed that the effectiveness of Eucalyptus terreticornis decreases with time and they therefore need constant reapplications. The resource poor farmers are recommended to use E. terreticornis at higher rates to control the Sitophilus zeamais. They also need to continuously add fresh E. terreticornis leaf powder at intervals as these lose their effectiveness with increased storage time.

\section{References}

1. Rukuni N, Towonezvi P, Eicher C (2006) Zimbabwe Revolution, maize Research and Development University of Zimbabwe Publication, Harare, Zimbabwe pp. 208-212.

2. Mulungu LS, Lupenza G, Reuben SOWM, Misangu RN (2007) Evaluation of Botanical products as stored Grain Protectant against Maize weevil, Sitophilus zeamais (L.) on maize. Journal of Entomology 4: 258-202.

3. Pingali PL, Pandey S (2001) Meeting world maize needs Technology opportunities and priorities for the public sector. In: Pingali PL (Ed.), CIMMYT 1999-2000, World maize facts trends CIMMYT, Mexico, USA, pp. 337-345.

4. Iloba BN, Ekrakene T (2006) Comparative assessment of insecticidal effects of Azadirachta indica, Hyptis suaveolens and Ocimum gratissimum on Sitophilus zeamais and Callosabruchus maculantus. J Boll Sch 6(3): 626-630

5. Owusu EO (2001) Effects of some Ghanaian plant components on control of two stored product insect pests of cereal. J stored product Res 37(1): 85-91.

6. Mbaiguinam M, Naura N, Bianpambe A, Bono G, Alladcumbaye E (2006) Effects of commom plant seed oils on survival, eggs lying and development of the cowpea weevil, Callosobruchus maculantus (F.) Coleoptera: brychidae. J Boll Sch 6: 420-425.

7. Greenberg SM, Showler A, TXLU (2005) Effects of neem-based insecticides on beet armyworm (Lepdoptera: Noctuidae). Insect Schi 12(1): 17-23.

8. Kubo I, Nakanish K (2001) Insect antifeedants and repellents from African plants in: symposition series No 62: host plant resistance to pests. The American chemical society pp. 165-175.

9. Stoll G (2000) Natural Crop Protection in the tropics, Verlog Joset margrat, Science Book, Germany pp. 221-224.

10. Aktar Y, Isman MB (2004) Comparative growth inhibitory and antifeedant effects of plant extracts and pure allelochemicals on four phytophagous insect species. J Applied Entomol 128(1): 32-38.

11. Gadzirayi CT, Mutandwa E, Chikuvire TJ (2006) Effectiveness of maize cob powder in controlling weevils in stored grain. African studies Quarterly 8(4): 6.

12. Duke JA (2001) Handbook of medicinal herbs CRC press, Bocd Raten, FL, USA, pp. 114-128.

13. Dolob P (2002) A practical assessment of food losses sustained during storage by small holder farmers in the shire valley Agricultural Development Area of Malawi Report of the Tropical products institute slough G138, p. 32.

14. Obeng-Ofori D, Amiteye S (2005) Efficacy of mixing vegetable oils with pirimiphos-methyl against the maize weevil, Sitophilus motchuisky in stored maize. J stored product Res 41: 57-66.

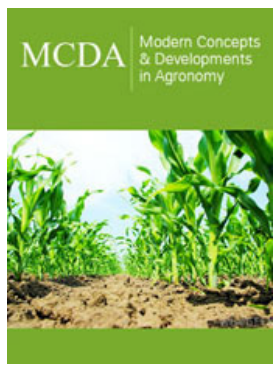

\section{Modern Concepts \& Developments in Agronomy}

\section{Benefits of Publishing with us}

- High-level peer review and editorial services

- Freely accessible online immediately upon publication

- Authors retain the copyright to their work

- Licensing it under a Creative Commons license

- Visibility through different online platforms 